\title{
Pendampingan deteksi mandiri sindrom metabolik melalui pemeriksaan IMT, obesitas sentral, tekanan darah, dan pemeriksaan kadar kolesterol
}

\author{
Susilawati*, Puji Rizki Suryani, Rara Inggarsih, Masayu Farah Diba, Septi \\ Purnamasari \\ Program Studi Pendidikan Dokter, Fakultas Kedokteran, \\ Universitas Sriwijaya, Palembang, Indonesia \\ E-mail: susilwt78@gmail.com
}

\begin{abstract}
Abstrak
Terjadinya pergeseran pola makan umumnya pada masyarakat di daerah perkotaan dimana komposisi makanan yang dikonsumsi cenderung lebih tinggi lemak dan rendah serat. Kualitas tidur yang buruk akibat pekerjaan yang padat juga menjadi faktor risiko timbulnya berbagai masalah kesehatan seperti hipertensi, obesitas, resistensi insulin dan dislipidema atau biasa kita sebut sebagai sindrom metabolik. Banyak penelitian menunjukkan bahwa angka kesakitan dan kematian akibat sindrom metabolik meningkat secara bermakna. Kegiatan pengabdian pada masyarakat ini berupa penyuluhan tentang meningkatkan kesadaran masyarakat di desa Talang Petai tentang bahaya sindrom metabolik. Tujuannya untuk meningkatkan kesadaran agar melakukan kegiatan pencegahan dan pemeliharaan kesehatan melalui pengaturan pola makan, pola tidur, memperbanyak aktifitas fisik, dan segera memeriksakan diri ke tempat pelayanan kesehatan setempat jika terjadi gejala dan tanda penyakit. Hasil dari kegiatan ini, didapatkan peningkatan pengetahuan masyarakat tentang bahaya berikut bagaimana upaya promotif dan preventif dari sindrom metabolik. Untuk selanjutnya, perlu dilakukan kegiatan pengabdian yang berkesinambungan kepada masyarakat sehingga derajat kesehatan dapat meningkat.
\end{abstract}

Kata kunci: Sindrom Metabolik, Obesitas, Kolesterol dan Tekanan Darah

\begin{abstract}
Assistance for self-detection of metabolic syndrome through examination of BMI, central obesity, blood pressure, and examination of cholesterol levels. The shift in eating patterns generally in urban communities where the composition of food consumed tends to be higher in fat and low in fiber. Bad sleep quality due to heavy work, is also a risk factor for various health problems such as hypertension, obesity, insulin resistance and dyslipidemia; we call it metabolic syndrome. Many studies have shown that the number of morbidity and mortality due to metabolic syndrome increases significantly. Community service activities in the form of counseling about raising public awareness about metabolic syndrome, especially people in the village of Talang Petai. Aim of this activity is to increase awareness to carry out prevention and health care activities through dietary arrangements, sleep patterns, increasing physical activity, and immediately check into a health service if there are signs and symptoms of disease. The results of this activity, there is an increase in public knowledge about the dangers and how to promote and prevent metabolic syndrome. Henceforth, it needs to be done continuous community service activities so that health status can be increased.
\end{abstract}

Keywords: Metabolic Syndrome, Obesity, Cholesterol, and Blood Pressure 


\section{PENDAHULUAN}

Faktor-faktor risiko penunjang terjadinya sindrom metabolik seperti usia, riwayat penyakit dan riwayat keluarga pada dasarnya hanya merupakan faktor pencetus yang jika tidak diimbangi dengan kesadaran untuk mengubah perilaku hidup menjadi lebih sehat baik dalam pola makan dan pola tidur serta aktifitas fisik tentu akan semakin meningkatkan kesempatan sindrom ini berkembang bahkan lebih cepat. Juga tidak dipungkiri, tidak memiliki faktor risiko belum tentu terhindar dari sindrom ini.

Desa Talang Petai merupakan salah satu desa yang berada di Kelurahan Plaju Darat, Kecamatan Plaju Sumatera Selatan. Berdasarkan data yang diperoleh dari Ketua RT setempat, diketahui jumlah penduduk pada tahun 2018 adalah 441 orang. Diketahui sebagian besar masyarakat jarang memeriksakan diri ke tempat pelayanan kesehatan terdekat sehingga deteksi dini sindrom metabolik tidak terlaksana.

Masih kurangnya pemahaman masyarakat tentang perilaku hidup sehat dan kurangnya kesadaran masyarakat untuk memeriksakan diri secara dini dalam upaya pemeliharaan kesehatan menjadi inti dari kegiatan pengabdian masyarakat ini untuk mensukseskan program "Gerakan Masyarakat Sehat" demi tercapainya peningkatan derajat kesehatan bangsa pada umumnya.

\section{TINJAUAN PUSTAKA}

Sindroma Metabolik adalah sekumpulan penyimpangan fungsi tubuh yang berupa obesitas sentral, tekanan darah tinggi, dislipidemia (peningkatan kadar kolesterol terutama $L D L$, trigliserid, dan rendahnya kadar $H D L)$, gangguan resistensi insulin maupun diabetes (Lingga, 2012). ${ }^{1}$ Sindrom metabolik adalah gangguan yang kompleks dengan biaya sosial ekonomi tinggi yang menjadi epidemi di seluruh dunia. Sindrom metabolik didefinisikan sebagai sekelompok faktor yang saling berhubungan yang secara langsung meningkatkan risiko penyakit jantung koroner (PJK), bentuk lain dari penyakit aterosklerotik kardiovaskular (CVD), dan diabetes mellitus tipe 2 (Rochlani, 2017). ${ }^{2}$ 
Prevalensi sindrom metabolik bervariasi di seluruh dunia dan sering berbanding lurus dengan prevalensi obesitas. Terdapat berbagai variasi dalam prevalensi berdasarkan usia, jenis kelamin, ras/etnis, dan kriteria yang digunakan untuk diagnosis. Sindrom metabolik mempengaruhi seperlima atau lebih populasi Amerika Serikat dan sekitar seperempat populasi Eropa. Asia Tenggara memiliki prevalensi sindrom metabolik lebih rendah tetapi dengan cepat bergerak menuju tingkat yang sama dengan barat. BeltránSánchez dan rekan melaporkan penurunan prevalensi sindrom metabolik yang disesuaikan berdasarkan usia di AS, dari 25\% pada 2000 menjadi 22,9\% antara 1999/2000 dan 2009/2010 berdasarkan data dari National Health and Nutrition Examination Survey-NHANES (Beltrán-Sánchez at. al., 2013). ${ }^{3}$

Prevalensi sindrom metabolik di Indonesia adalah 21,66\% dengan prevalensi provinsi berkisar antara 0 hingga 50\%, sedangkan prevalensi etnis berkisar antara 0 hingga 45,45\%. Dua komponen sindrom metabolik yang paling umum di Indonesia adalah kolesterol HDL rendah dan hipertensi (Herningtyas, 2019). ${ }^{4}$ Disability Adjusted Life Years (DALYs) menjadi faktor risiko yang terkait dengan sindrom metabolik termasuk BMI tinggi, tekanan darah tinggi, glukosa plasma puasa tinggi, kolesterol total tinggi (Institute for Health Metrics and Evaluation, 2013). ${ }^{5}$

Komponen diagnostik utama antara lain penurunan kolesterol HDL, peningkatan trigliserida, tekanan darah dan glukosa plasma puasa, yang semuanya terkait dengan penambahan berat badan, khususnya akumulasi lemak intra-abdominal / ektopik dan lingkar pinggang yang besar. Sindrom metabolik menggandakan risiko penyakit kardiovaskular, tetapi menawarkan pendekatan pengobatan yang efektif melalui manajemen berat badan. Sindrom metabolik sekarang menyerang 30-40\% orang pada usia 65 tahun, terutama didorong oleh penambahan berat badan orang dewasa, dan predisposisi genetik atau epigenetik terhadap akumulasi lemak intra-abdominal/ ektopik yang berhubungan dengan pertumbuhan intra-uteri yang buruk. Sindrom metabolik juga dipicu 
oleh kurangnya jaringan adiposa subkutan, massa otot rangka yang rendah, dan obat antiretroviral (Han, 2016). ${ }^{6}$

Menurut Kamso (2011)7, karakteristik demografi, gaya hidup, jenis kelamin, dan aktivitas sedentari berhubungan dengan sindrom metabolik. Zahtamal (2014) juga menyatakan bahwa aktivitas fisik yang kurang (sedentary lifestyle) berhubungan dengan kejadian sindrom metabolik. Mekanisme patogenik dari sindrom metabolik sangat kompleks dan memerlukan penjelasan yang komphrehensif. Variasi luas dalam distribusi geografis sindrom metabolik baru-baru ini di negara berkembang menekankan bahwa faktor lingkungan dan gaya hidup seperti konsumsi kalori berlebih dan kurangnya aktivitas fisik sebagai kontributor utama. Adipositas visceral telah terbukti sebagai pemicu utama untuk sebagian besar jalur yang terlibat dalam sindrom metabolik, sehingga menekankan asupan kalori yang tinggi sebagai faktor penyebab utama (Matsuzawa et al, 2011). 9

Modifikasi gaya hidup tetap menjadi intervensi awal pilihan untuk sindrom metabolik. Terapi modifikasi gaya hidup modern menggabungkan rekomendasi khusus tentang diet dan olahraga dengan strategi perilaku. Perawatan farmakologis harus dipertimbangkan untuk mereka yang faktor risikonya tidak berkurang secara memadai dengan perubahan gaya hidup. Bagi orang yang kelebihan berat badan / obesitas dapat mengurangi berat badan $>7 \%$ hingga 10\% selama periode 6 hingga 12 bulan. Penurunan berat badan harus dikombinasikan dengan minimal 30 menit aktivitas fisik intensitas sedang setiap hari. Terapi nutrisi membutuhkan asupan lemak jenuh dan total yang rendah; mengurangi konsumsi gula sederhana dan makanan indeks glikemik tinggi; dan peningkatan asupan buah, sayur, polong-polongan, dan biji-bijian. Statin dapat dikombinasikan dengan fibrat dan niasin untuk mencapai tingkat target LDL-C, trigliserida, dan HDL-C. Lebih lanjut, mayoritas pasien yang membutuhkan terapi antihipertensi kemungkinan akan membutuhkan lebih dari satu agen untuk kontrol tekanan darah yang tepat dengan ACEI / ARBs dan beta blocker / Thiazides / CCBs sebagai 
agen lini pertama dan kedua. Metformin, thiazolidinediones, dan acarbose akan menurunkan risiko diabetes mellitus tipe 2 pada penderita IFG atau IGT (Kaur, 2014). ${ }^{10}$

Untuk itu, amat penting sekali upaya edukasi serta upaya preventif dan promotif lainnya sehubungan dengan perubahan gaya hidup modern menuju pola hidup yang lebih sehat untuk mencegah komplikasi dan gejala yang ditimbulkan dari sindrom metabolik seperti penyakit jantung koroner, hipertensi, obesitas dan diabetes mellitus.

\section{METODE}

\subsection{Khalayak Sasaran}

Khalayak yang menjadi sasaran dalam kegiatan pengabdian ini adalah masyarakat dan kader kesehatan di wilayah Kelurahan Tegal Binangun RT 30 RW 05 desa Talang Petai, Kelurahan Plaju Darat, Kecamatan Plaju sebanyak kurang lebih 50 orang. Tujuan kegiatan ini untuk membuat peserta mampu mengenali secara dini tanda-tanda umum sindrom metabolik, faktor risiko dan prognosisnya, bagaimana upaya pencegahan dan pemeliharaan kesehatan serta peningkatan kesadaran untuk melakukan pemeriksaan kesehatan.

\subsection{Keterkaitan dan Keterlibatan Mahasiswa}

Kegiatan pengabdian masyarakat ini melibatkan 5 orang dosen dari fakultas kedokteran Universitas Sriwijaya dan 5 orang mahasiswa dari Fakultas Kedokteran.

\subsection{Metode Kegiatan}

Kegiatan pengabdian masyarakat berupa upaya edukasi dan kegiatan skrining pada gangguan sindrom metabolik menggunakan metode

a. Edukasi kesehatan (penyuluhan) dan pemberian leaflet

Dilakukan dengan pemberian informasi melalui ceramah dan diskusi serta pemberian leaflet kepada masyarakat tentang tanda-tanda umum sindrom metabolik, faktor risiko, prognosis dan komplikasi penyakit, edukasi tentang pola makan dan tidur yang sehat 
serta pentingnya aktifitas fisik sebagai salah satu cara pencegahan dan pemeliharaan kesehatan.

b. Skrining dan Demonstrasi

Skrining sindrom metabolik dengan pemeriksaan fisik (Indeks Massa Tubuh/ IMT dan lingkar pinggang), pemeriksaan tekanan darah serta pemeriksaan kolesterol dan glukosa darah sewaktu dilanjutkan dengan konsultasi kesehatan serta peragaan kepada masyarakat terutama kader kesehatan, mengenai cara penggunaan alat pemeriksaan,

c. Pemantauan

Pemantauan dilakukan untuk mengetahui keberhasilan dari kegiatan yang telah dilaksanakan oleh dosen dan mahasiswa.

\subsection{Rancangan Evaluasi}

Rancangan evaluasi ini diperlukan untuk mengetahui tingkat keberhasilan dari kegiatan. Adapun evaluasi dilakukan dengan 3 tahap, yaitu :

Tahap 1: Analisis potensi lokasi pengabdian (dilakukan saat penyusunan proposal).

Melalui tanya jawab dengan kader kesehatan dan ketua RT setempat tentang tanda-tanda umum dan faktor risiko sindrom metabolik.

Tahap 2: sebelum dan saat kegiatan berlangsung.

Evaluasi ini diperlukan untuk mengetahui pengetahuan masyarakat tentang gangguan sindrom metabolik. Edukasi tentang pola makan dan tidur yang benar serta pentingnya aktifitas fisik dengan pemberian pre test sesaat sebelum dilakukan penyuluhan dilanjutkan dengan peragaan dan pelatihan keterampilan kepada kader kesehatan dan masyarakat tentang cara pemeriksaan menggunakan kit digital.

Tahap 3: pada saat akhir kegiatan.

Untuk mengetahui keberhasilan kegiatan dilakukan post test agar dapat diketahui peningkatan pengetahuan masyarakat tentang sindrom metabolik setelah dilakukan penyuluhan dan peragaan. 


\section{HASIL DAN PEMBAHASAN}

Kegiatan pengabdian kepada masyarakat ini dilaksanakan pada hari Sabtu tanggal 9 Oktober 2019. Kegiatan ini diikuti oleh warga masyarakat setempat serta kader kesehatan dengan jumlah 50 orang (usia 45-60 tahun). Pelaksanaan pengabdian ini berjalan dengan lancar. Kegiatan dimulai dengan memberikan pretest dilanjutkan dengan penyuluhan kepada peserta pengabdian tentang "Gangguan Sindrom Metabolik", mulai dari tandatanda umum, faktor risiko serta komplikasi yang dapat ditimbulkan. Edukasi tentang pola makan dan tidur yang benar serta pentingnya aktifitas fisik sebagai tindakan pencegahan dan pemeliharaan kesehatan juga diberikan.

Masyarakat diedukasi tentang pentingnya deteksi dini gangguan sindrom metabolik agar pengobatan yang tepat dapat segera diberikan dan komplikasi yang tidak dinginkan dapat dicegah. Selanjutnya dilakukan pengenalan kepada para kader dan masyarakat tentang alat pemeriksaan digital tekanan darah kolesterol total darah, dan glukosa secara cepat, fungsi dan kegunaan alat, indikasi pemeriksaan, bagaimana cara penggunaan alat tersebut, dan cara pengambilan sampel darah kapiler serta cara membaca hasil pemeriksaan.

Masyarakat juga dijelaskan kapan harus memeriksakan diri ke fasilitas kesehatan terdekat jika muncul gejala umum yang sering terjadi pada gangguan sindrom metabolik. Penyuluhan dilengkapi dengan pemberian leaflet agar informasi kesehatan yang diberikan saat penyuluhan dapat dibaca-baca ulang di rumah.masyarakat juga diperkenankan untuk konsultasi mengenai penyakit yang sedang mereka atau keluarga mereka alami. Ada juga beberapa warga yang berobat, walaupun dalam kegiatan pengabdian ini penyelenggara tidak menyiapkan obat-obatan, sehingga warga yang minta untuk diperiksa dan berobat

dibuatkan resep oleh para dokter yang bertugas. Terlihat masyarakat sangat antusias dan besemangat untuk konsultasi dan diskusi tentang gangguan sindrom metabolik.

Pada akhir acara para peserta memberikan kesan dan pesan sehubungan dengan kegiatan yang telah berlangsung. Pemberian posttest dilakukan untuk mengukur 
peningkatan pengetahuan peserta setelah diberikan penyuluhan dan hasilnya menunjukkan peningkatan nilai rara-rata yang cukup signifikan dibanding saat pretest.

\section{SIMPULAN}

Kegiatan pengabdian pada masyarakat yang telah dilaksanakan, telah menambah wawasan dan pengetahuan masyarakat dan kader kesehatan tentang gangguan sindrom metabolik. Peserta kegiatan memahami tanda gejala umum, faktor risiko, komplikasi, upaya promotif dan preventif yang dapat dilakukan, serta kewaspadaan untuk segera memeriksakan diri ke fasilitas pelayanan kesehatan setempat bila terdapat tanda dan gejala. Selain itu warga dan kader kesehatan juga telah memiliki keterampilan untuk melakukan pemeriksaan tekanan darah, kadar kolesterol total dan glukosa darah secara mandiri dengan baik dan benar.

\section{Ucapan Terima Kasih}

Penulis mengucapkan banyak terimakasih sebesar-besarnya kepada semua pihak yang telah membantu sehingga pengabdian ini dapat terlaksana dengan baik, terutama kepada Rektor Universitas Sriwijaya, Ketua Pusat Pelayanan dan Pengembangan Lembaga Penelitian dan Pengabdian (PPP-LPPM) UNSRI, Dekan FK UNSRI, Ketua RT 30 RW 05 desa Talang Petai, Kelurahan Plaju Darat, Kecamatan Plaju Serta masyarakat.

Terima kasih juga kepada Fakultas Kedokteran Universitas Sriwijaya yang telah mendanai pelaksaan kegiatan pengabdian kepada masyarakat ini. Sesuai dengan Surat Perjanjian Pelaksanaan Kegiatan Pengabdian Kepada Masyarakat Fakultas kedokteran Universitas Sriwijaya. Nomor: 109/011/UN9.1.4/PLP-PPM/PL/X/2019, 1 Oktober 2019.

\section{Referensi}

1. Lingga L. Program anti-X tanpa obat, Sindrom X: Diabetes tipe-2, hiperkolesterolemia, dan hipertrigliserida, hipertensi, dan obesitas. Jakarta: PT Elex Media Komputindo. 2012.

2. Rochlani Y, Pothineni NV, Kovelamudi S. and Mehta JL. Metabolic syndrome: 
pathophysiology, management, and modulation by natural compounds. Therapeutic advances in cardiovascular disease. 2017;11(8): 215-25.

3. Beltrán-Sánchez H, Harhay MO, Harhay MM, McElligott S. Prevalence and trends of metabolic syndrome in the adult U.S. population, 1999-2010. Journal of the American College of Cardiology. 2013;62(8): 697-703.

4. Herningtyas EH and Ng TS. Prevalence and Distribution ff Metabolic Syndrome and Its Components Among Provinces and Ethnic Groups in Indonesia. BMC public health. 2019; 19(1): 377.

5. Institute for Health Metrics and Evaluation. The global burden of disease: generating evidence, guiding policy. 2013

6. Han TS and Lean MEJ. A clinical perspective of obesity, metabolic syndrome and cardiovascular disease. JRSM Cardiovascular Disease. 2016;S: 1-13.

7. Kamso S, Purwantyastuti, Lubis DU, Juwita R, Robbi YK, Besral. Prevalensi dan determinan sindrom metabolik pada kelompok eksekutif di Jakarta dan sekitarnya. Kesmas: National Public Health Journal, 2011;6(2): 85-90.

8. Zahtamal Z, Prabandari YS and Setyawati L. Prevalensi sindrom metabolik pada pekerja perusahaan. Kesmas: National Public Health Journal. 2014;9(2): 113-120.

9. Matsuzawa Y, Funahashi T and Nakamura T. The concept of metabolic syndrome: Contribution of visceral fat accumulation and its molecular mechanism. Journal of Atherosclerosis and Thrombosis. 2011;18(8): 629-39.

10. Kaur J. A comprehensive review on metabolic syndrome. Cardiology research and practice. 2014 